\title{
Child's Play: Illustrated Bodies and Traces of Disability
}

\author{
Eve Lacey \\ 14 Newmarket Road \\ Cambridge \\ CB5 8DT \\ el303@cam.ac.uk
}

07812594489

This work was supported by Newcastle University and Seven Stories museum under the David Almond Fellowship 2012 


\title{
Child's Play: Illustrated Bodies and Traces of Disability
}

\begin{abstract}
This article examines traces of disability in children's literature, interrogating the opportunities for readerly play through which the child and the text may formulate character and plot in tandem. It focuses on instances of ellipsis and writing on the body in the works of David Almond and Jacqueline Wilson, and lauds the dependency of the incomplete, excessive or 'crip' text. Just as queer and critical disability theory reveal the cultural construction of bodies, so too texts come into being through a series of social, technical and infrastructural supports. The article explores obstacles to the articulation of illness and literary techniques overcome that silencing stigma, to express the unutterable and so lift the quarantine between the sick subjects and their readers. A close examination of missing text and tattoos on fictional bodies reveals the ways in which authors foster a culture of interdependency in storytelling, in which the plot occurs at the intersection between reader and writer, and so disassemble the illusion of a selfsufficient body of work. The fragmented text makes plain this mutual dependency and so functions as a narrative prosthesis which figures the child reader as implicated in, rather than immune to, the stories of disabled characters.
\end{abstract}

\section{Keywords}

disability; children's literature; Jacqueline Wilson; David Almond; crip theory 8480 words 
In 'Reading and Writing "Immunity": Children and the Anti-Body', Robert McRuer identified two categories of children's fiction on HIV/AIDS in 1980s America: those texts that implicated the child reader and those that assumed them to be immune. Embodying AIDS in a neighbourly avuncular figure and eliciting pity from child readers was negligent, he argued, because it assumed that the child's interaction with HIV would only ever be stretched to tolerance, that their own serostatus would never be in question and that they would not grow up to join one of the at-risk groups. In effect, the children's literature that figured disability at a distance assumed its young audience to be white, middle-class and healthy, and imagined that these factors were unlikely to change or be compromised as they grew.

There exists a longstanding literary tradition of disability as either lack or excess - whether of body, sexuality, or morality - and a deviation from a strictly symmetrical able body. An 'able-bodied' text is likewise of perfect proportions and balance - its plot is linear and whole, omitting no detail of the story and offering no surfeit of text. It professes to exist omnisciently and without the assistance of a reader. Of course, like the ideal of the able-bodied human, this can never really be achieved. Just as disability studies teaches that all bodies are dependant on social, technical and infrastructural support, so too books are reliant on the social (readers and critics), the technical (the printing process) and the infrastructural (bookshops and libraries) to tell their story. The marginalia surrounding a book's production - the drafts, correspondence, and marketing strategies - gives some clue as to the extent of this interdependency.

Since the early twentieth century and the advent of New Criticism, theorists have debated what makes a book whole, whether the lone text is sufficient or whether work can only be considered complete in relation to its social context. One of the first accomplishments of disability studies was to parallel this literary conundrum 
with the question of bodily wholeness, and so shift the diagnosis of 'wrongness' from the individual onto the social context: people were not disabled, rather, society was disabling. Scholars of the medical humanities have since expanded on this dominant social model to consider the physical realities of illness and to posit impairment on a continuum. A similar continuum should recognise the slippery slope between reading and meaning-making. In literary terms, lumps and lacks serve to exaggerate the fallibility of language, which always misses the mark. Texts that are underwritten, overwritten and demand readerly participation leave traces of disability in their wake; they become 'crip' - a critical term for 'imaging bodies and desires otherwise'. ${ }^{i}$ Writing by traces invokes a heuristic response to disability that allows the child reader to form disabled bodies by implication and interaction rather than a straightforward pedagogy of liberal tolerance, and ensures that storytelling becomes a medium through which to encounter and identify with physical and mental difference.

David Almond's writing often manifests a spirit of dependency, and three works in particular explicitly acknowledge their own imperfection: Skellig, the story of an ailing man who lives in a young boy's shed; Heaven Eyes, in which three children escape from an orphanage to befriend a strange girl with webbed feet and no past; and Kit's Wilderness, one boy's struggle to help his troubled friend through storytelling. In addition to the study of missing or superfluous texts, there is the writing on bodies within these books. Tattoos have a strong association with permanency, but the surface they mark is infinitely more changeable than the pages in a book, and the ink is blurred, stretched and scarred as the body beneath is inscribed with age and experience. Jacqueline Wilson's The Illustrated Mum and her portrayal of bipolar disorder through body art demonstrates the narrative significance of tattoos, as the means through which the protagonist establishes her own character and as a plotting device for the structure of the book. 
Tattoos and other forms of corporeal inscription form a metaphor for the body as text, they 'crip' the child reader's experience to acknowledge the ways in which all bodies are, to some extent, written. Equally, tattoos go some way towards making the book corporeal; if the body surface figures itself through indelible design, so the book grows bodily as it wears its contents on its sleeve. The disabled body is often constructed as that which transgresses its bounds. Margrit Shildrick scrutinizes bodies that are characterized by a 'putative leakiness, the outflow of the body which breaches the boundaries of the proper', ii and disabled bodies seem to be the leakiest of all. They are seen to spill into the space outside of themselves, revealing too much and, at the same time, leaving their own insides woefully deficient. If the body is understood as 'a discursive construction, marked by environmental process and power, but given to us only in texts' $(L B B, 15)$, we can begin to understand the importance of books to the narration of normality in contemporary medical discourse, where a healthy body is deemed to be the neutral state upon which illness marks an aberrant intrusion. The industry and comprehension of books must then be considered alongside the social structures that inform definitions of disability, in order to expose the linguistic work that goes into marking illness as a leak and maintaining the normalcy of the body proper.

Bodies of writing require play if they are to be read. Roland Barthes introduced the notion of jouissance in The Pleasure of the Text, a concept of active and playful engagement with language. Readerly play is not only pleasurable, it is a crucial component of the act of meaning-making. Lennard Davis notes that listeners do not so much understand speech as they do frantically decode it into 'preconstructed categories' until the shape of new words is dictated, like building block toys, by the shape of the vessel they slot into. ${ }^{\text {iii }}$ This game of deciphering and shape-sorting - pleasure with a pedagogic twist - is child's play. ${ }^{1}$ Just as an infant will try several different shapes

This is not to suggest a universal condition of childhood. This essay focuses quite specifically on textual engagement, which will not be the way in which all children encounter disability. I evoke the figure of the child reader as that which is traditionally constructed as immune, but which these texts 
before eventually fitting the triangle block into the triangular slot, so 'the receiver of speech is continually improvising to make the act of talking make sense' ( $E N$, p. 19). It is this preconstructed dictionary, which will only accommodate new text on its own terms, that fully accounts for the authorial role of the reader. The play between preconstructed and received words becomes all the more apparent when the text is somehow flawed, or the game encounters an error: a gap in the text reveals sorting behind the scenes.

Where Barthes's jouissance implies a sensual pleasure, child's play denotes an equally sophisticated, if perhaps more destructive force. With child's play, the game teeters closer to the verge of that which cannot be articulated and engages more thoroughly with the language that is not there: when Almond writes sentences with missing words or words with missing letters, the reader's own dictionary comes into play. As a result, shape-sorting can quickly become shape-shifting, when the child's play crosses over from interpretation to composition and becomes writerly in the process. Fictional bodies are plotted at the playful intersection between the writing and the reader's existing imaginative framework and so words are never received exactly as they were meant: they are shapes to be sorted according to the child's own imagination, and when the author's intended shape does not fit, it is shifted accordingly. The layers of over- and under-writing in the work of David Almond and Jacqueline Wilson create palimpsests of texts that incite child's play - Almond implores children to fill in the lacunae of his stories, and Wilson composes a meta-text which she invites the children to imitate. Their narratives depict disabled bodies as a means of 'cripping' the text itself and so undo the artifice of the story that claims to be whole, or the body that masquerades as natural.

The Missing Text

In David Almond's Skellig, disability is paramount. The mysterious eponymous trouble by implication in verbal and bodily disfigurement through play. 
character is written elliptically, and he can appear ethereal because for so long, so little of him is described. Almond primes his readers for a subject who is largely unknown, personified by an absence of clarity that Michael and Mina must trust. One trope of Skellig's elusive nature is his reluctance to be introduced, referring to himself as a byword for illness rather than an independent and separate entity:

I am nearly nobody. Most of me is Arthur. [...] Arthur-itis. ${ }^{\text {iv }}$

With this introduction, Almond allows his eponymous hero's identity to occupy the negative space left by a wasting disease. Again, when he first meets Mina, Skellig identifies primarily in terms of the disability that has consumed his entire being: "You're Mina, I'm Sick to Death" ( $S$, p. 73). Here, Almond plays with ontological ambivalence, promoting illness from the transitional or additional trait to the primary identifier until Skellig becomes sickness embodied.

Skellig exudes an air of negation that suggests he is threatening to disappear altogether. By taking such a non-entity of a character and positioning him as the prime subject of the novel's enquiry, Almond redresses the focus of 'plot' and forces a lacuna to centre stage, which in turn pushes his child readers, like Mina and Michael, to revisit Skellig's obscurity. But the lacuna in question is not really blank, not devoid of any determining significance; in each introduction, the 'lack' in question is clearly aligned with disability. Thus Almond's lacunae are 'cripped', bearing traces of illness that are expectant, pregnant with a meaning to be contributed by the reader.

Almond reiterates the trope of illness as lack with Michael's younger sister, who hovers somewhere between a fragile life and death and haunts the book at its margins. Joy is not named until the final page - Michael's little sister is a body not yet written, and her namelessness suggests that her parents are afraid to invest the ink of a name on a child who may not survive. Once again, Almond forces a lack of discussion to the fore - where disabled experience is so often silenced, the unspoken 
part of his story is made the most significant and, in a disavowal of able-bodied linguistics, the child reader is trained to pay closer attention to unutterable illness.

While Michael can hardly bring himself to mention his sister, he channels anxiety through the man in the shed. To some extent, Skellig is a figment of Michael's imagination and a means of exploring his sister's mortality. In this sense, Skellig's 'nothingness' redoubles on itself: he is not even a gap in his own right, but rather the projection of someone else's gap. The novel comes to a close after Skellig visits the ailing baby in hospital and she recovers from an operation to be named Joy. This climax presents a kind of double negativity to healing and a philosophy of caring interdependence whereby 'Joy' comes firmly into being once blessed by the fading man who is nearly nobody at all.

For the double negative of a mutual lack, the salve is mutual dependency; an infrastructure of care and support is required for either or any subject to survive. In the 'Examined Life' film, Judith Butler and artist Sunaura Taylor discuss the 'false idea that the able-bodied person is somehow radically self-sufficient'. ${ }^{\mathrm{v}}$ Their discussion reveals that the need for assistance is universal, a reality that is frequently overlooked in an ableist, neoliberal society in which individualism is championed as the aim and norm. Such critical focus on interdependency serves to destabilise the whole and promotes the imperfection that Almond insists upon in his work. This silence, the reticent lack inhabited by Skellig's most fragile characters, can be simultaneously disabled and curative, and its reliance on interaction empowering.

A similarly dual subjectivity can be seen in early drafts of Heaven Eyes, in which Heaven Eyes appears as the first person narrator and remembers her own naming:

She called me Caroline at my birth, but as I grew she gave me my true name, Heaven Eyes. [...] 'Heaven Eyes,' she used to whisper. 'That's who you are and 
what you are, because you see through all the grief and trouble in the world to the Paradise that lies beneath. ${ }^{, \mathrm{vi}}$

By the time the novel was published, the above version of Heaven Eyes had split in two. Erin Laws, of Whitegates orphanage, assumed the first person role and recollection of her mother, and Heaven Eyes was estranged, placed on an island in the Black Middens and deprived of any memories of her parents. Her direct line to the reader was severed, her speech disfigured and her blind optimism focalized through Erin's wonder at the angelic, alien child.

Almond admits that the same division of characters occurred in the process of writing Kit's Wilderness, whose working title was 'Quiet Michael in the Wilderness'. Quiet Michael, who at first seemed a very important character to Almond, eventually blended into John Askew, the wretched boy who plays a game called Death. In both instances, the most troubled character has, in the process of completion, been drawn back and told through the viewpoint of a child, like Erin or Kit, who is at once more 'normal' and dragged into a spiritual and foreboding world by the shadowy characters who used to occupy the novels' central roles.

In Heaven Eyes, the Black Middens of the river Tyne function as a stretch of unknown from which curiosities intermittently emerge. Erin, January and Mouse venture into the dark waters on a raft and find themselves washed up by a printing works whose only inhabitants are Heaven Eyes and her Grampa. During their stay, the children find a 'saint' in the slime, a body preserved in the blackened mud. Similarly, in The True Tale of the Monster Billy Dean, Billy finds parts of Christ's body in the rubble and his mother says 'mebbe well fynd mor [...] Mebbe well fynd evrythin of Jesus \& mayk him agen'. ${ }^{\text {vii }}$ Such allusions display Almond's tendency towards transubstantiation in children's investigation; he bestows upon the lacunas of water the uterine power to give forth mysterious bodies or relics, rendered celestial by a child's 
faith.

Just as Almond's amorphous bodies of water yield remnants of the Biblical, so too his disfigured words proffer literary fragments whose semantic value is greater than the sum of their letters. Broken words serve as a neurological exercise in which linguistic gaps are deciphered by association and difference. Engagement with unfamiliar words has been identified as a key attribute in language learning since 1958, when Jean Berko Gleason created the Wug test to explore the acquisition of morphemes. According to this test, children as young as four are usually able to conjugate a pseudo word (such as 'wug') into different tenses, simply by applying the rules they have learnt elsewhere. This test relies on the fact that children, to a far greater extent than adults, exist in a world that only makes partial sense, and that their every external engagement must be a gamble on meaning inferred rather than confirmed. The wayward application of grammatical rules serves to stress the learnt social behind the verbal, and proves that all understanding is contingent on guesswork and a performance of acquired experience.

In The Case of Peter Pan, Jacqueline Rose identifies a trend in children's literature whereby adults project innocence onto childhood and strive to keep the young immune from the ills of the world by keeping the language as simple and unequivocal as possible. At odds with this tradition, Almond and Wilson implicate the child reader in meaning-making and so refuse to quarantine the figure of the child from the dirty work of language. Almond has a 'general aesthetic of experience as valuable', and, in Heaven Eyes, experience is manifest in broken words and damaged skin. ${ }^{\text {viii }}$ Where children's literature might traditionally seek to teach or protect, these works argue for a greater exposure to 'wrongness' and suggest that skin should be marked with the endeavour. They are willing to invite meaning where there is none stated, to embrace a reciprocity between language and its reader and so endorse an ephemeral, age-specific interdependency similar to that cited by Butler and Taylor. Childhood, the 
only point in an individualist society when one cannot be blamed for dependency, is also the one time that nobody expects language to function in flawless self-sufficiency. Taking Barthesian jouissance to its logical extreme, child's play revels in the words that are not there, and the language that does not masquerade as an able-bodied text.

But if children are liberated from the burden of individualism, they are also the social group most likely to be assumed immune from the text. These two diagnoses undo each other - where the first might allow the reader and text to interdepend, the child's assumed immunity limits the productivity of their play. In this case, the adult counterpart is the critic, who is also most commonly portrayed as dispassionate. Though they arrive at the state from different directions - the child is immune by virtue of his innocence, the critic by her knowledge - the end result is of a strikingly similar isolation from the text. However, closer attention to the marginalia of writing betrays the involvement of both these readers in text formation: correspondence with editors illustrates the role of the critic at the earliest stages of creative writing, and Wilson's diaries show how she writes in dialogue with herself as a child, as well as the hundreds of children from whom she receives fan mail.

In Heaven Eyes, Almond invites his reader to fill in the gaps of a broken language. The eponymous heroine was raised in a derelict printing works by the 'C RET KER' [caretaker] and so, from the gaping shores of the Black Middens, Almond figures a language cratered with holes. ${ }^{\text {ix }}$ In this example, the lexical choice cannot be overlooked - the 'C RET KER' is only partially present and the author is not entirely there to supervise the reader with fully spelt-out words. All is not present and correct, and the omission of complete care, the lack of didactic guidance, allows the reader to play with the text more freely.

Play is an act of meaning-making, and explicit ciphers in the text make space for that exchange. While no writer, hampered and harnessed by language, 
can portray an utter lack of meaning, Almond succeeds in at least alluding to the presence of that lack. In the notes for Heaven Eyes, he hints at the reflexive possibilities of a hunt for comprehension: 'What do you find? Depends what you're looking for' (DA/01/01). If readers cannot think beyond language then language is all that they can look for, but engaging with the chase illuminates the possibility of something inarticulable in their peripheral vision. Virginia Woolf stresses a link between inarticulacy and disability in On Being Ill: '[T] literature, there is the poverty of the language'. Such a dearth of vocabulary, symptomatic of a silencing social stigma, reinforces the textual association between disability and gaps in the text. If language perpetuates the able-bodied ideal with an abundant lexicon of beauty and strength, then the voice of the disabled body is held in sufferance and repeatedly muted.

In Staring, Rosemarie Garland-Thomson exacts a similar notion of the hunt for legibility on the text of the disabled subject: staring is an interrogative gesture that demands a story. The eyes hang on, working to recognise what seems illegible, order what seems unruly, know what seems strange. ${ }^{\mathrm{xi}}$ Such an organising gaze can equally be applied to reading and re-reading 'unruly' words. The gaps in Almond's texts elicit a reciprocal stare in which the reader requests a moment to linger. Within the printing works in Heaven Eyes, where important documents are stored out of the children's reach, Almond places physical abnormality on a par with a pidgin 'home' language to illustrate Grampa's judgement that 'It is a wrongness in you, little one' ( $H E$, p. 58). Here, in addition to her webbed feet, Heaven Eyes is cripped linguistically and the missing vowels in 'C RET KER' come to signify a corporeal disfigurement as well as a symbol of hidden information.

In the very early notes for Heaven Eyes, the mutual cripping of character and text becomes most apparent in a profile for 'Patch', whose appearance is 
fleetingly described: 'gammy leg - left' before the text is obscured by the torn page. Hidden letters and missing pages create a porous text with no foreseeable endpoint. Letters exchanged between David Almond and his editor demonstrate this prospect of the never-ending text, as their correspondence suggests that the author has been tempted to amend his work long after publication, drawn to scribbling in the margins of copies on WHSmith shelves. Here, too, the book's becoming is dependent on an interaction between author, infrastructure and critic.

Writing on the Skin

In Narrative Prosthesis, David Mitchell and Sharon Snyder argue against the notion of the prosthetised body as especially deficient. Instead, they dub the able-bodied ideal 'a thoroughly artificial affair'. xii They show how all bodies are infinitely inscribable, and that '[d]isability's representational "fate" is not so much dependent upon a tradition of negative portrayals as it is tethered to inciting the act of meaning-making itself' $(N P, \mathrm{p}$. 6). Disability is all too easily made into metaphor and too often made shorthand for moral or social ills. The language of disability - blindness, limping, and loss - is highly figurative and it is this quality that makes mentions of impairment such fitting narrative prostheses: each term speaks volumes.

In Heaven Eyes, Almond proposes a thoroughly textual ontology: '[t]he letters make words and words make us' (HE, p. 62). Words on the skin of fictional characters expose the extent to which somatic conditions are inscribed to their assigned bodies and entirely narrative in their function. The extra layer of writing is a prosthetic addition to the story beneath, a loaded metaphor piled on top of the literal, until writing on the skin functions as a redoubling of the author's storytelling. Metaphor, employed in this way, initiates a re-imagining of disability in the mind of the reader. Rather than transposing the lived realities of disability onto the text, it deals in slippery referents and perhaps, in its transposition, enacts a relational model of disability, which cannot occur in isolation. 
Playing with the terminology of disability initiates a self-reflexivity that makes visible the textual nature of normalcy and stigma and invites the reader to linger longer over silences.

If the semantic association between disability and interdependency is new, it is also hopeful: metaphor entails the beginnings of fantasy, and fantasy

allows us to imagine ourselves and others otherwise; it establishes the possible in excess of the real; it points elsewhere, and when it is embodied, it brings the elsewhere home. .iii $^{\text {in }}$

Metaphor, then, is prosthetic to the story because it is excess to reality, and plots are propped up on the promise of a different future. Rose notes that children's literature often seeks to emulate innocence through realism, to stick as close to lived experience as possible: 'The linguistic sign is superfluous and misleading' and realism in children's literature is 'that form of writing which attempts to reduce to an absolute minimum our awareness of the language in which a story is written'. ${ }^{\text {iv }}$ According to this reading, language itself is a deviation and excess, and drawing attention to the craft of writing constitutes a betrayal of reality, which becomes un-innocent in imitation. In these terms, metaphor is a gross excess of signification and, simultaneously, exposes a gross inadequacy to capture the real on its own terms. The abstraction of figurative language underscores the body of a book, and exposes the constructed nature of its production. In its lumps and lacks, a metaphor does not settle for realism - it demands an addition in excess of the real - and this language lends itself to bodies that figure differently to others, those that seem to matter more or less, those that leak more or less textual significance and which, in their imbalance, expose the linguistic work behind the careful equilibrium that they threaten to break.

In Heaven Eyes, the industry of letters is laid bare in the form of a derelict printing works, where the activity of word-construction manifests as spare alphabet 
pieces strewn around an old factory. For the child reader, broken bodies of fiction are momentarily allowed primacy, cripped works can be the chief mode of identification, and an excess of text can bring the elsewhere home.

Both Wilson and Almond depict characters whose bodies are literally drawn on, with pens and needles and knives. In The Illustrated Mum, Marigold gets a tattoo for every memorable moment in her life. In contrast to the negative space of a disabled presence in Skellig, Marigold's tattoos ensure that the disabled body is hyper-visible, both as colourful pigment and as an explicitly narrative device. Wilson makes Marigold's illustration inseparable from her mental illness and so binds the 'crip' aspect of her nature to a surface that is incorrigibly narrative. Her ink grows to eponymous significance, it plots her body around key life events and constitutes the very structure of the novel as each chapter bears the name of one of her tattoos. In short, the tattoos and their stigma make a storybook of Marigold; her disability is flaunted and made integral to the telling of the tale. In My Name is Mina, Almond associates written skin with mental illness and self-punishment. Like Marigold, Mina is drawn to the canvas of her skin and considers carving words into her arm, but she refrains from confessing this to her classmate who has a history of self-harm. Even without full consciousness of tattoos' association with incarceration and contaminated needles, Mina recognises that body modification is the realm of the embattled or distressed - those with a 'wrongness' in them - and that writing on her own skin would join the wider text of their oppression and so render her body legibly troubled.

Writing on the skin forces the body to be read as a meta-text, as open to interpretation as the story itself. For Almond's Billy Dean, the semi-literate storyteller and angel of a post-apocalyptic island, skin is infused with religious potency and words written on a fleshy page gain spiritual weight. So Billy decides to write his first book on a Frankenstein construction of small animal skins grafted together. 
According to Billy and his father, the relationship between skin and ink is mutually beneficial; just as the skin lends gravity to the words, so the words promise unnatural longevity: 'as long as the book exists its as if the beests hav got eternal life' ( $B D$, p. 42). So words can animate organic material beyond its own lifespan, infused with a wider story and fraught with textual significance.

In this sense, Almond recognises the performative nature of body art. Words on skin cannot contain themselves, they leak and bleed quite literally beneath the surface and imbue the carrier's body with further meaning. Tattoos constitute a reclamation of the body's oppression and impression, and a statement of ownership over one's own exhibited vulnerability. In Heaven Eyes, this statement is most clearly embodied in Mouse, who frequently pulls up his sleeve to reveal the " $p$ LeAse LoOk after $\mathrm{mE}$ ' that his father etched onto his skin before leaving him at Whitegates orphanage. The tattoo acts as a compulsive narrative, telling the story of its bearer almost against his will:

there he was again, trembling and sobbing and showing the tattooed words on his arm again while Maureen cooed and pulled the tale out of him. (HE, p. 15) Mouse has been written by one parent figure, and read by another. While neither figure is an adequate carer (his father leaves, and Maureen sees her charges as doomed), the writing on Mouse's skin demands that its subject be looked after. His tattoo is the ultimate cry of dependency, etched with his father's own vulnerable admission that he is unable to look after his son himself. But the declaration of weakness worked. The instruction of the tattoo is followed, not just by Maureen and Whitegates orphanage, but also by Mouse's peers, Erin and January.

Tattoos can also offer a protective form of stasis, a kind of endurance that Steven Connor dubs 'cryogenic survival'. ${ }^{x v}$ In My Name is Mina, Steepy applies this stab at immortality with an ecological twist: 
He lifted his shirt. There was a whole garden tattooed on his chest: hedge, trees, dozens of flowers, butterflies, birds.

“That's just the bloody start. I'll get a bloody forest on me legs, mountains on me back, bloody sky on me bloody head." ${ }^{\text {xvi }}$ [my italics]

Here, Steepy extends his dermatological identity beyond the individual and towards a greater environmental good. His adornment is not only permanent on him, it also preserves the nature that humans endanger and force towards expiry. The tattoos are 'works of bloody art...' - the very adjective he uses to emphasise its status as artwork also describes the pain and sacrifice of inscribing skin. The greenery of Steepy's garden takes root from the blood split by the inky needle. As a simulacrum of the real plants taking their nutrients from composted carbon and animal remains, so Steepy's flora and fauna exploit the bloody body beneath their surface. The tattooing process drew blood, quite literally.

It is a resolute statement indeed from someone so young that their body will be expected to change multiple times over the course of growing up. It is also a move that spurns the whimsy of a changing zeitgeist and trends, or the assumption that a person's beliefs should mature with age. With his fleshy garden, Steepy defies the progress of consumerism on two counts: he first challenges the consumption and desecration of the natural world, and then he forces his youthful skin into a kind of fashion stasis, in which his body will always be 'a bloody monument' to the lost botanic (MNIM, p. 228).

There is a Peter Pan quality to such a statement on the body of a young boy: not only does he preserve the garden, he also refuses to bow to the notion that childish flesh should only be marked by growth, that it should remain otherwise unblemished until it reaches maturity. Mina responds to Steepy's tattoos with the exclamation "But you're just a boy!" and Steepy admits that his uncle performed the tattoos illegally, and he will have to wait until he is sixteen to continue the shrine 
(MNIM, p. 227). Almond depicts Steepy's back as a site of subversion, not only of Western notions of beauty and the able-bodied, but perhaps more fundamentally by attributing to a minor's body the potential for 'forever'. With this pregnant gesture, Almond disregards the assumption that a child could only ever regret such a lasting decision in later life. In privileging the permanence of Steepy's statement, he skews time in favour of youthful determination, places botanic remorse above the chronological sequence of regret, and thus hails the child's body as a canvas for rebellion and radical conservation.

Wilson illustrates Marigold's disability with an excess of text, and her protagonist is covered with multiple layers of ink and paint. Marigold's body art is relentless. Her response to the tattoos as signs of 'weirdness' is not to cease but to recover her ink with white paint, and when she is hospitalised she takes a biro to her arm and continues to draw. With the language of her skin white-washed, Marigold begins to talk in a trance:

Not dry. Wet. So I can't sit down. I can't lie down. I can’t. But that's OK. It will be dry and so will I. And so will I. And then I'll be right. I'll be white. I'll be a good mother and a good lover and Micky will bring Star back and we'll be together for ever and ever, a family, my family, and it will be all right, it will, it will, I will it, it has to be better. It couldn't be worse, this is a curse. But it will be better better better, no more tattoos, Star hated them, she hated me, but now they're gone, until the laser, could I use a razor? No, too red, I want white, pure light, that's right... ${ }^{\text {xii }}$

This rhyming and repetitive language mimics the compulsion of Marigold's body art. The purging of her tattoos coincides with a moment of highly stylised logorrhoea, and extra layers of paint generate a compulsive confessional. Just as the body art can only be remedied with yet more illustration, so her story can only be told with another stream of 
language. For Marigold, silence is not an option, and her body will not cease its signification.

It is significant too that Wilson chose to position the moment of crisis at the point of masking Marigold's body art. Throughout the novel the eccentricity of a multi-coloured skin is something to be embraced, along with its implicit deviation from the able-bodied norm. Unfortunately, this authorial decision is not always recognised in analysis of the book: in an episode of Radio 4 Bookclub dedicated to The Illustrated Mum, several audience members questioned how children would react to the upsetting description of Marigold's mental illness. Such questions cast the child reader in the problematic role of a privileged outsider to the story. In lending a platform to these concerns at the expense of others, for whom the experience of caring for a mentally-ill family member would be recognisable and its fictional representation reassuring, the programme perpetuated a culture of adults in the thrall of innocence, and children 'immune' to illness rather than 'implicated', as McRuer suggests is the most effective way for children's literature to narrate to disability and disease.

The Illustrated Mum demonstrates the ways in which tattoos can signify a cripness worn with pride, an attempt to flaunt and exhibit an illness that might otherwise be suffered alone. Wilson's writing crips a surface, as a blemish and as a dermatological tale that subverts the dichotomy of permanence and change, allowing space for youth without innocence and marks that preserve but do not save. In this sense, writing on the body is analogous to a published book: in one sense permanently 'finished', in the other, subject to the constant evolutions of the impression it leaves upon others.

\section{Scabs and Subjectivity}

If the finished tattoo functions to some extent as a social signifier, then the process of tattooing serves to reaffirm the body's subjectivity. Woolf noted that ' $[\mathrm{t}]$ he impressions 
of childhood are those that last longest and cut deepest'. xviii With this easy alignment of an influenced mind and a scarred body, Woolf's metaphor reasserts the ontological significance of skin as a site of experience. Almond also uses marked skin and blemished bodies as legible manifestations of experience. His aesthetic denies the typical 'future orientation' of children's literature and positions childhood in a teleological conundrum, often disposed towards the prehistoric $(R C L, 3)$. Most notably, the narrator in Kit's Wilderness conflates the troubled character John Askew with Lak, an imagined boy from the Ice Age. The choice of name in both cases underlines the lacunae incorporated into John's character: a la[c]k renders him deviant and askew. Rather than portray children as the site of as-yet unwritten futurity, Almond situates his children within a flexible historicity and one that they are able to over- and underwrite as they see fit.

Experience disfigures its subject and even healed wounds can leave a scar. In The Book of Skin, Connor suggests that the childish habit of picking scabs amounts to a reckoning with vulnerability and survival: a 'gathering-together of the self is achieved, not in the face of potential loss or trauma, but through it' (BOS, p. 52). In Kit's Wilderness, John Askew's game of Death embodies a child's play with danger and the marks it leaves behind. Kit and his friends play this game in the gaping abyss of an abandoned mine as they struggle to comprehend the deaths of children their own age, with the same names, in the same place. The scab of Askew's wildness is picked at intermittently, mediated through the meta-text of Lak, until Kit is able to come to terms with his friend's worrying proximity to danger and grows bold enough to venture into his hiding place and coax him out.

Just as Askew's story is gathered piecemeal, broken and filled with Lak, so Almond's lacunae constitute a parallel 'gathering-together' of the book simply by testing its boundaries and traumatising its unblemished form. A text riddled with 
lacks plays with the notion of its own annihilation and incorporates the prospect of no text within the text itself. My Name is Mina is the most emphatic example of this project, with scrawling fonts, white-on-black text and blank pages that draw stark attention to the possibilities of 'a story in which nothing happens at all' (MNIM, p. 241).

When Woolf expressed wonder at the canon's failure to articulate illness, she also suggested that disabled utterances are prone to candour and nonsense in equal measure, similar to Marigold's rhyming stream of consciousness:

There is, let us confess it (and illness is the great confessional), a childish outspokenness in illness, things are said, truths are blurted out, which the cautious respectability of health conceals. $(O B I$, p. 17)

\section{$[\ldots]$}

Incomprehensibility has an enormous power over us in illness, more legitimately perhaps than the upright will allow. (OBI, pp. 27-28)

Illness cries out for a language that is not yet there. An expression of disability must first encounter resistance from a self-censoring language; one that has 'all grown one way' and that will class descriptions of sickness as 'blurted out', rather than thought through - language figured as a bodily compulsion rather than a measured, cerebral and socially acceptable statement (OBI, pp. 6, 17). In The Illustrated Mum, Wilson stresses the social stigma behind such linguistic failure. In her preliminary notes, Wilson capitalises 'DON'T TELL', which was suggested as an alternative title along with 'The Weirdos'. Marigold's youngest daughter Doll is gagged by fear, unable to articulate her mother's problems for fear that she and her sister will be taken into care. Doll's dyslexia only compounds her reluctance to express her worries verbally. However, where words fail, pen and ink images find new space for articulation on Doll's own skin and that of her friends. Rather than shy away from the attention garnered by her mother's illustrated skin, Doll seeks to imitate this particular mode of self-expression. 
Almond, on the other hand, confronts verbal failure with lacunae that assume the space of this crip confessional, and symbolise the peculiar inadequacy of language when it comes to disability. Neologisms arise through distortions in the form of absence and as well as lexical creativity. If we view

\section{'C RET KER'}

as a new word, rather than a mistake, we see a word that incorporates the gaps that are usually only found between words. Thus Almond challenges the very concept of 'whole', not only writ large in book form, but also on a minute verbal scale: the gaps within a single unit are equal to the spaces between units and the individual is not expected to function at any higher level of completion alone than with others. When one word is several, its fragility reinforces the interdependency of the wider sentence structure. 'C RET KER' is only still a word because the reader fills in the gaps. Such a lexical breakdown also draws attention to the reader's ability to infer and insinuate according to a shared knowledge and grammar, and so the interdependency that Almond illustrates on a syntactical scale also reflects the mutual reliance of writer on reader, and vice versa.

In the notes for Heaven Eyes, the Black Middens comes to embody this perilous and life-affirming gap:

We struggled to free ourselves. [...] The more we tried to save ourselves the more we were drawn in. (DA/01/02/01/02)

We kept slipping backwards, collapsing, making body-shaped pools in the Middens. (DA/01/02/01/01)

These drafts depict a river that both sucks and spews, a darkness with a morbid allure. Another instance of 'gathering together' through abrasive ordeal, Almond's Middens permits the three adventurers to lose themselves in a journey of self-discovery and allows the sticky substance of the unreadable text to become saturated with hidden 
secrets.

Almond takes the prospect of illness and death and plays with it to produce 'a visual compromise between lesion and healing'; his ruptured prose and weighty silences become the method of incorporating illness and marginality into his work stylistically (BOS, p. 51). The presence of ellipses blemishes the page so that vulnerability - as a textual trope, social stigma and corporeal reality - is brought into sharp focus. A trace of disability therefore betrays the book's fragility, it is an absence to which he has repeatedly returned, a scab picked at until it scars.

Troubling Innocence and Implicating the Reader

Wilson is determined to trouble the notion of childhood innocence. Her childhood diary stated a hostility towards a cloistered, censored fiction:

If I ever write I won't write for children. I can't understand how Enid Blyton can write all day, yet leave out everything about real life. Her families don't quarrel, her parents don't nag, her teenagers aren't interested in lipstick and boys, her children never listen to dirty stories or wet themselves, and she ignores babies and pregnancy and sex $[\ldots] .^{\text {xix }}$

There is evidence that both Almond and Wilson actively encourage their child readers to immerse themselves in the aspects of their works that deal with what Wilson here refers to as 'real life', but which could also be read as the most evidently troubled. In the proof copy of Heaven Eyes, Almond addressed his 'Dear Reader':

I hope that you will enjoy the book, and that you too will step aboard the children's raft, to be carried downriver into the unknown, into the mysterious world of Heaven Eyes, who sees through all the darkness in the world to the joy that lies beneath. (DA/01/01)

This invitation to dive into his murky Black Middens is a direct call for optimistic enquiry and a child's play that finds enchantment in the mire. More directly, Almond's 
Mina urges the readers of her notebook to take part in an 'extraordinary activity' and 'write a page of words for joy' (MNIM, p. 133). Here, jouissance is something to be discovered in negative space and, like Michael's little sister, Joy can only be named in the lack that Skellig left behind. Almond's elliptical style functions similarly to the paint covering Marigold's tattoos: the white spaces can only half conceal the marks beneath and so create a pentimento through which the work of storytelling and the omissions of disability in standard speech are laid (almost) bare. This semi-transparent writing style bestows upon the child reader a greater responsibility to engage with the text and actively construct the body of the story.

Like Woolf, Elaine Scarry bemoans our lack of language for illness and argues that pain is characterised by its 'unsharability': empathy is finite, anyone not in pain remains immune to the agony and quarantined by the deficiencies of language. ${ }^{\mathrm{xx}}$ But Wilson finds extra-textual ways around this obstacle and manages to implicate her readers. A letter from her editor at Random House reveals that Wilson suggested giving away temporary tattoo transfers with copies of The Illustrated Mum. ${ }^{\text {xi }}$ This promotion is perhaps the most stark example of the implicated child reader and, notably, it prompts identification with the mother, rather than Doll, who is the first person narrator and peer of the vast majority of Wilson's readers. Far from shying away from Marigold's mental illness, or attempting to protect children from its unhappiness, Wilson explicitly encourages children to bear the marks of 'The Weirdos'. Wilson fittingly asks the reader to transfer Marigold's symptoms onto their own skin, to temporarily inscribe themselves with her fiction and write their own bodies through the example of a bipolar woman.

While this can only ever amount to a commodified and transient imitation of Marigold, it draws child readers into a position of agency over their own bodies and towards the realisation that their skin is written, that difference is inscribed 
and that it can fluctuate over time. If only for a short period, the child reader may acquire a body with extra illustration and invite the lingering glances that entails. Thus, by including this offering alongside her work, Wilson radically overturns the assumption that child readers are 'already and always immune' and proposes a fiction of transferring traces back and forth. Such an infectious representation of illness renders the process of reading a process of interpreting disability, it encourages the child reader to encounter and, briefly, embody narratives of physical or mental difference.

In Almond and Wilson's work, disability presents itself not only as a medical or cultural identity category but also as textual practice. The traces of disabled bodies betray fractured novels and the 'wrongness' in missing or superfluous text. In exposing the latent vulnerability of the book, these two writers surrender their work to the child reader, dismantle the able-bodied text and allow a culture of interdependency to flourish within children's fiction.

Textual lacks and excesses oscillate between two forms of ableist gaze: the all-too-lingering and the all-too-fleeting, something read twice or not at all. The notion of tattoos as indicative of the hyper-visible disabled body and of the absent text as the negative space of a disabled presence may initially appear as antithetical means of portraying disability, but in practice they do the same work and both threaten the text's undoing as a stable category. Rather than undermining each other, or indeed filling each other in, the importance of these techniques lies in their deviation from the norm. Regardless of direction, be it a lack or a lump in the text, these aberrations from the linear plot work in duality to reveal and champion the interdependent nature of reading.

As authors distance themselves from a caretaking narrative role, they open the door to a more engaged child readership. A reliance on collaboration will always imply an element of the unfinished and the daunting prospect of the never- 
ending text. Even in its published form, the uneven text bears traces, or scars, of the drafting process which entails a demystification of the book as a tangible entity with a beginning, middle and an end. The reader can feel the graft and partake in the surgery.

So a text can be disabled if it is read as anything other than whole. Tattooing remains the most visible manifestation of the literary entrails of our flesh and bones; it entails an evisceration of the text in which reading becomes an act of disembowelling, dragging words through the body on their way to making sense. Perhaps the greatest blow to an ableist society is the recognition that its ideal of a whole, functioning and stand-alone body is fallacious, and impossible to achieve. Literary theory would do well to observe a comparable failing, to divest the book of all its mythical powers of signification and entertain the notion that the text is entirely external to the body of work.

Disabling a book, acknowledging its lumps, lacks, and dermatological abrasions, exposes more sites of interactive interpretation and so promotes a radical capacity for empathy which could lift the quarantine between the reader and disabled subject, character or text, and construct a figure of the child that is implicated rather than immune. For Marigold, Steepy and Mouse, bodily embellishment correlates with greater textual significance: these marked figures are somehow more inked than the rest, their 'wrongness' is acutely visible and their illustrated bodies constitute an extra layer of writing traced onto the body of the text itself. Almond and Wilson produce works that necessitate the interaction of child's play, and so illustrate that all narratives, like all bodies, require prostheses - no book is immune to the scars of drafting or above the crutch of a reader's intuition. 
i Robert McRuer, Crip Theory (New York and London: New York University Press, 2006) p. 32.

ii Margrit Shildrick, Leaky Bodies and Boundaries (London and New York: Routledge, 1997), pp. 16-17; hereafter abbreviated $L B B$.

iii Lennard Davis, Enforcing Normalcy (London and New York: Verso, 1995) p. 19; hereafter abbreviated EN.

iv David Almond, Skellig (London: Hodder Children's, 1998) p. 29; hereafter abbreviated S.

v Judith Butler and Sunaura Taylor, Examined Life (https://www.youtube.com/watch?v=k0HZaPkF6qE)

vi David Almond, notes, drafts and proofs of Heaven Eyes in Seven Stories archives, Newcastle. Reference: DA/01/02/01/01; Hereafter abbrevaited DA/reference.

vii David Almond, The True Tale of the Monster Billy Dean telt by hisself (London: Puffin, 2011) p. 108; hereafter abbreviated $B D$.

viii Kimberley Reynolds, Radical Children's Literature (Basingstoke: Palgrave Macmillan, 2010) p. 22; hereafter abbreviated $R C L$.

ix David Almond, Heaven Eyes (London: Hodder Children's, 2000) p. 56; hereafter abbreviated $H E$.

x Virginia Woolf, On Being Ill (London: Hogarth Press, 1930) p. 12; hereafter abbreviated OBI.

xi Rosemarie Garland-Thomson, Staring: how we look (Oxford and New York: Oxford University Press, 2009) p. 3; hereafter abbreviated St.

xii David Mitchell and Sharon L. Snyder, Narrative Prosthesis: disability and the dependencies of discourse (Ann Arbor: University of Michigan Press, 2000) p. 7; hereafter abbreviated NP.

xiii Judith Butler, Undoing Gender (New York and London: Routledge, 2004), pp. 28-29.

xiv Jacqueline Rose, The Case of Peter Pan (London: Macmillan, 1984), p. 46; p. 65.

xv Steven Connor, The Book of Skin (New York: Cornell University Press, 2004) p. 64; hereafter abbreviated BOS.

xvi David Almond, My Name is Mina (London: Hodder Children's, 2010) p. 227; hereafter abbreviated MNIM.

xvii Jacqueline Wilson, The Illustrated Mum (London: Corgi Yearling, 2000) p. 158.

xviii Virginia Woolf, The Common Reader: First Series (New York: Harcourt Inc, 1925) p. 54.

xix Jacqueline Wilson, diary from the age of 15, 1961 (on display at the 'Daydreams and Diaries' exhibition at Seven Stories museum in 2012).

Ex Elaine Scarry, The Body in Pain (Oxford and New York: Oxford University Press, 1985) p. 4

xxi Letter from Random House to Jacqueline Wilson relating to The Illustrated Mum and other books, 1998 (on display at the 'Daydreams and Diaries' exhibition at Seven Stories museum in 2012). 